\section{THE CAUSES OF SCOLIOSIS AND THEIR RELATION TO TREATMENT *}

Z. B. ADAMS, M.D.

Surgeon to Orthopedic Out-Patient Department, Massachusetts General Hospital; Fellow in Anatomy, Harvard Medical School

BOSTON

No one biased in his belief should attempt the study of either the causes or treatment of scoliosis. We must approach the subject with an open mind. Each case is a problem in itself.

The treatment of structural lateral curvature is now advancing apace with our knowledge of other medical and surgical problems. This has been made possible by the investigations of Drs. Bradford, Lovett, Feiss and Forbes, and of late the study of the subject has been stimulated anew by the announcement of Dr. Abbott of Portland. Drs. Bradford and Lovett ${ }^{1}$ studied the motions of the normal human spine in its various positions. They found there was no sidebending without rotation and no rotation without sidebending. They also found these motions were more free in flexion.

Lovet ${ }^{2}$ experimented with the column of bodies and disks without their posterior segments and found it obeyed the laws of physics for flexible columns.

Feiss studied the complex problems of rotation and lateral bending, both by experiments on the living and by a mechanical model of the thorax and a model of a vertebra with its attached ribs.

Dr. A. McKenzie Forbes, of Montreal, impressed by the failures of all methods to procure the so-called forcible correction with plaster jackets, undertook a further study of the subject to explain and rectify the knowledge.

He has discovered a paradox, which is this: Given a case with right dorsal rotation, the only way to reduce this rotation is to rotate the body trunk to the right. His discovery was made by observations of a scoliotic subject with radiograms, and an exhaustive study of the work of Lovett and Feiss. This rotation is in exactly the opposite direction to that practiced by Abbott and all previous operators in attempting correction. In brief, Forbes puts his patients in a position of extreme flexion and rotation. They are then held in this position by plaster jackets with large windows.

In structural lateral curvature, we are dealing with a condition, not a discase. There are many causes of scoliosis, but they are not so multitudinous and are, in general, of a very different character from what an inspection of the literature would lead one to suppose. Bad seating at school, faulty postures, malleability of the vertebrae, osteomalacia, rachitis, infantile paralysis, empyema, numerical variations, extra and fused ribs, lateral half of a centrum missing, fused vertebrae, etc. -all have a bearing on the subject, some, but not all of them are true causes. In short, have not, many times, the contributing factors been mistaken for the true cause?

When one remembers the small seats in school for the rapidly growing child, the difficulty of getting

* Read before the Section on Orthopedic Surgery at the Sixty-Fifth Annual Session of the American Medical Association, Atlantic City, N. J., June, 1914 .

1. Bradford and Lovett: Orthopedic Surgery, Philadelphia, William Wood \& Co., 1911.

2. Lovett, Robert W.: Lateral Curvature of the Spine and Round Shoulders, 1912. one's knees under the desk, the curled up and sidetwisted position in which we were taught to write, and yet no scoliosis developed, has not in this case the contributing factor been mistaken for the cause? We all sat curled up and sidewise when in school and while growing rapidly, yet no scoliosis developed.

Rachitis, osteomalacia and other bone softenings go into the same list. We have all seen profound rachitis without scoliosis.

Short leg, from whatever cause, and many other so-called causes are subject to the same criticism. Scoliosis occurs in some cases in which they exist, but if they are the cause, why does it not occur in all? The answer is, they may be a contributing factor, but they are not the cause.

Some years ago, Dr. Böhm ${ }^{3}$ beautifully elaborated the theory of numerical variation, advanced by Rosenberg, to account for some of the anomalies which occur in the spine and its appendages. Possibly he has since expanded this theoretical garment to envelop spina bifida and all the rest of Nature's defects in the human frame.

Dr. Böhm stated in his paper that asymmetric sacralization might cause a lateral tilting of the top of the sacralizing vertebra and thus cause scoliosis. An inviting supposition, but it does not prove to be the cause in many cases of scoliosis.

Roentgenograms of the scoliotics at the Children's Hospital showed but few in which there was asymmetrical sacralization, and in these few, the top of the sacralizing vertebra was not tipped. At the Massachusetts General Hospital, in taking roentgenograms of subjects with indefinite pains in the back, or when renal or ureteral stone, etc., is suspected, asymmetrical sacralization in all degrees is often found but there is no scoliosis. If ever a cause it is a rare cause.

The Dwight Collection of spines in the Warren Museum further bears this out. Of the nineteen spines showing asymmetric sacralization but one has scoliosis, and that one also shows an absence of the right neural process of the first sacral segment, which is of far greater importance, so far as the cause of the scoliosis is concerned. But Dr. Böhm aroused interest in the anomalies of the spine and the effects they might produce, and for this deserves great credit.

Some three years ago in checking up the work of Dr. Böhm the conclusion was reached that so far as the cause of scoliosis is concerned, congenital defects of the articular processes were of far greater importance than asymmetric sacralization.

The weight of the trunk and upper extremities is largely borne by the flexible column of the vertebral bodies and disks, but it is also supported in a varying degree by the two more rigid posterior columns of the articular processes. Thus the support is tripedal.

With this in mind, we can all see how a missing half of a centrum, a wedge-shaped centrum, whether congenital or pathologic, or an extra osseous center on one side between the bodies, will cause lateral deviation and rotation, hence lateral curvature.

Such cases are rare; however, they form a class which show certain characteristics of their own, especially when they occur in the upper dorsal and cervical regions. The deformity usually appears early in life. They originate from defects in the embryo about the sixth week.

3. Böhm, Max: A Contribution to the Etiology of Lateral Curvature of the Spine, Boston Med. and Surg. Jour., Jan. 25, 1905; The Cause 
Anomalies of the sacrum, involving its neural arch or articular processes are very common. Dr. Goldthwait has already drawn the attention of orthopedic surgeons to these facts and has shown their relation to back strain.

Obstetricians realize the variations in inclination of the female pelvis, and the varying degrees of prominence of the fifth lumbar body, and Dr. Lloyd Brown has made clear the importance of these facts in the production of back strain and ptosis. In the female the average sacrovertebral angle is considerably (13 degrees) greater than in the male.

The late Professor Thomas Dwight once said, "Anomalies of the fifth lumbar vertebra are so common that we hardly know what the normal should be." This is equally true of the sacrum.

Sir William Turner, the famous English anatomist, found separation of one or both of the inferior articular processes of the fifth lumbar vertebra in 5 per cent. of all subjects. The pedicles of this vertebra occasionally fail to unite with the body; spina bifida is frequent in the lumbosacral spine.

Now realizing that the base on which the column of bodies and disks rests-namely, the facet on the upper surface of the sacrum-is not directed upward, but is distinctly inclined forward as well as upward, having a pitch of 40 degrees from the horizontal in the average female, and that this pitch varies in individuals, being often much greater than 40 degrees in women, and that the only bony obstacles to the forward coasting of the fifth lumbar body on this steeply inclined surface are the articular processes in which anomalies are so frequent, one or both being separate ossicles in 5 per cent. of all persons, is it remarkable that under such conditions, the fifth lumbar body should slip forward and hence downward on this incline? At 45 degrees of inclination a movement of onefourth of an inch forward gives one-fourth of an inch drop.

The structures preventing this forward slipping are ligamentous, with the exception of the inferior articular processes of the fifth lumbar, above rnentioned, which articulate with or hook on to the superior articular processes of the sacrum. With increase of the vertebrosacral angle comes increase of this tendency to slide forward, hence an increased strain, vertical as well as horizontal, on these four small processes. As the inclination increases, the horizontal thrust becomes greater and more vertical, that is, the two forces tend to a pure downward strain on the processes; thus in the standing position a large part of the weight is thrown on them.

The ligamentous structures which support this joint are the fibers of the intervertebral disk, which normally allows a certain excursion; the anterior common ligament which here is thin and broad; the posterior common ligament which is narrow at this level; the ileolumbar ligaments rumning from the transverse processes of the fourth and fifth vertebra to the crests of the ilia; the lumbosacral ligaments running from the lower edge of the transverse processes of the fifth lunstur vertebra to the top of the sacrum; the subflavous ligaments binding the lower edge of the lamina to the top edge of the sacral lamina; the interspinous and supraspinous ligaments and the articular, capsular ligaments about the articular joints. All these ligamentous structures, like other ligamentous structures of the bodv, are capable of being slowly stretched.
As a hypothesis let us take a patient in which one of these four articular processes is imperfect, or is detached from the centrum, or let one pair be so turned that they face outward and inward, while their fellows of the opposite side face backward and forward, or one pedicle may have failed to unite with the centrum. Under any one of these conditions, the whole support on one side would be ligamentous, while bony and ligamentous support is on the other side. The body of the fifth lumbar vertebra would sag forward and clownward on one side, while it is held back on the other, hence, lateral rocking occurs with rotation of the base on which a compound mast, the spine, stands.

There will be a spondylolisthesis of one side. One side of the fifth lumbar body will swing forward about the articular process of the other side as a pivot, and due to the inclined upper surface of the sacrum will drop downward. The result of rotary motion of these two surfaces is well illustrated by a round stick sawed across at 40 degrees of inclination and the cut surfaces slightly rotated on one another.

Now suppose that the bony mass of one of these articular processes is increased in bulk, just as the transverse process of one side is increased in asymmetric sacralization. The vertebra will be pushed up by one leg of its tripedal support. We get forward and lateral tilting combined. Or if there is absence or marked undergrowth of one process, we get a backward and lateral dropping. Either is equivalent to combined side-bending and rotation, hence scoliosis. It is analogous to a camera on a level floor with one short or long leg to its tripod.

As the contributing causes, short leg, bad postures and seating, etc., have all been mistaken for the true cause. So have coexisting anomalies such as asymmetric sacralization and fused and extra ribs been mistaken for the true causes. All who have studied many roentgenograms realize the frequency with which multiple anomalies are found. In fact, it is ustual to find several anomalies of varying degrees in one individual, hence the multiplicity of congenital causes recorded for scoliosis.

Anomalies of the spine may occur at any point, but they are more frequently found where a freely movable region joins one in which motion is less free, as the dorsal with the lumbar, or the lumbar with the sacral. As shown above, the joints of greatest consequence, so far as the site of the cause of scoliosis is concerned, are those in which the surfaces between the centra have a sharp downward inclination, the lumbo. sacral and those between the sacral segments. The sacral segments do not begin to fuse until the seventh or eighth year, and this fusion between the first two segments is often delayed. The articular processes between the sacral segments are always small and often very irregular, hence the first sacral segment may rotate on the second. This is especially found in cases in which the first sacral segment is anomalous. In rare cases it occurs between the second and third segments. The presence of an anomaly at the base of the spine even in scoliotics, does not prove that anomaly to be the cause of the scoliosis. Each case must be studied carefully, as regards the mechanical principles involved.

As the degree of forward slipping or drop depends not only on the character and magnitude of the lesion, but also on the inclination of the sacrum and extent of the conseguent dorsal and lumbar anteroposterior 
curve, so the character of the scoliosis, caused by the same anomaly, may vary in different individuals.

The frequency of these anomalies in scoliotics is well illustrated by the clinic of the Massachusetts General Hospital. Of fifty consecutive cases in which careful roentgenoscopy has been made by Dr. Walter Dodd and Dr. Holmes, forty-four subjects showed bony defects in the sacrum or two lowest lumbar vertebrae.

Of the four patients showing no such lesions, two have infantile paralysis of five years' duration, involving the back muscles; one presents a case of syringomyelia; the others showed sharp dorsal curves with lateral deviation and rotation of the lumbar spine, but no bony anomalies in the lumbar or sacral region.

In the forty-four remaining cases above mentioned, the lesions found are as follows:

Anomaly of inferior articular processes of fourth lumbar $\ldots \ldots \ldots \ldots \ldots \ldots \ldots \ldots \ldots \ldots \ldots \ldots \ldots$. $\ldots \ldots \ldots$.

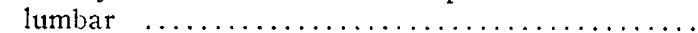

One large transverse process of fifth lumbar, Böhm

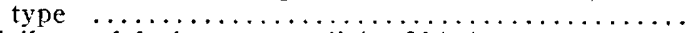

Failure of fusion, one pedicle, fifth lumbar........ Overgrowth of right articular process of sacrum... Undergrowth of right articular process of sacrum.. Articular process of sacrum forward............

Spina bifida first sacral segment with deformed

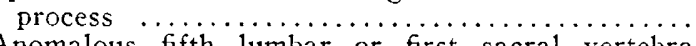
Anomalous fifth lumbar or first sacral vertebra

which has rotated......................... 12 cases

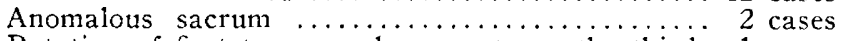

Rotation of first two sacral segments on the third. 1 case

Collapse of one ilium..................... 1 case

This gives an outline of what may cause scoliosis. Mistakes in interpretation may have been made, but by the assistance of Drs. Dodd and Holmes the findings in most of them are correct.

This study brings out the value of the flexed position. In attempting correction, not only should the thoracic spine be flexed, but the lumbar spine should be flexed on the sacrum, and the sacrum flexed on the lumbar spine; for flexion separates the articular processes and helps to get the sacrum forward under the spine.

The supine position with the foot-sling helps to draw the pelvis up and forward, while gravity pulls the trunk downward.

This study also suggests that in some of these cases, and possibly in many, operation should either precede or follow correction. In the first class it should be to replace the fifth lumbar centrum to its position on the sacrum, or to remove asymmetric overgrowth of the processes, which prevent restoring the base to a position of equilibrium; and in the second class to prevent recurrence of the deformity by means of bone graft to lock the fifth centrum to the sacrum; or on the articular processes to hold the vertebra in its place.

It is evident that the lumbo-sacral region is not thought to be the only region in which is found the congenital causes of scoliosis, but it is one of the most frequent sites of the cause in those cases occurring in girls about the age of puberty. At that age the lumbosacral angle increases, that is, the downward pitch of the inclined base; the ligaments are soft, due to rapid growth; the epiphyses have not all united, especially those of the iliac crest to which the iliolumbar ligaments are attached; and the body-weight is increasing.

Careful roentgenographic study of the whole spine is indispensable before any treatment of scoliosis is undertaken. Stereoscopic roentgenograms best show the position of the fifth lumbar vertebra in relation to the surrounding structures. In early cases the radiograms should be taken with the patient standing in order to show the position of the base in lordosis and in weight-bearing.

By the procedures of Forbes and Abbott some of the deformities of the spine may be corrected, but by these methods nothing has been done to remove the cause of the scoliosis. Will the corrected spine be able to maintain its equilibrium on the unstable base, from which this spine has already fallen? Should not this point be considered before subjecting a patient to the discomfort of a forcible correction?

I wish to thank Dr. Dodd and Dr. Holmes for their interest and assistance in this work.

166 Newbury Street.

\section{ABSTRACT OF DISCUSSION}

Dr. Harry Hudson, Philadelphia: About 1908, I reported a case of congenital scoliosis with not only structural but also numerical variation. There were thirteen ribs on one side and fourteen on the other; two supernumerary vertebrae were interposed, and there was fusing of two of the ribs. This case showed me the possibilitics in the way of structural changes as the cause of scoliosis; and while I have not carried out studies on this, as Dr. Adams has done, I have been careful in my roentgenoscopies since then. I now have four cases of asymmetrical sacralization of the lumbar vertebrae; one case of supernumerary half-vertebra interposed, causing an angulation of the spine; and another case of numerical changes in the ribs. I theorized considerably on this question but I did not have the energy to carry the theory out, that many cases of scoliosis must be due to some congenital malformation. That is, we cannot explain why children of ordinary good physique and musculature should suffer from so-called faulty positions, when other children of less muscular ability who have been subjected to the same conditions do not seem to have any trouble. This point should be investigated, and if we follow that line in roentgenoscopies in our cases of scoliosis we shall find more frequently, probably, minor changes in the facets and the spine. $I$ think that they are often there and are a deciding factor in so-called cases of static scoliosis.

Dr. Johx Duxlop, Washington, D. C.: Dr. Adams did not seem to go very much into the question of treatment. What has he to suggest in that line?

Dr. Z. B. Aduas, Boston: With regard to the question of numerical variation, I would call attention to the admirable work of Dr. Böhm, in which he followed out Dr. Rosenburg's thcory of cranial or caudal progression, to explain the occurrences of the various anomalies. Certainly Böhm deserves tremendous credit. I think that although in Germany Dr. Kollicker has done some work licfore, yet this work of Böhm was excellent. Many of these changes, however, are not due to numerical variation; that is, to asymmetrical sacralization. It is possible to have this in all degrees without any scoliosis. Asymmetrical sacralization is found in Roentgenray clinics. In taking roentgenograms for suspected stone in the kidney or pain in the back we find the broad wing and no scoliosis, and this is borne out by the collection in the Warren Museum. Out of this collection there was but one that showed scoliosis, and that one shows asymmetrical sacralization with the absence of the neural arch of the first sacral segment. This allows the fifth lumbar vertebra to tilt back on one side, hence is the cause of the scoliosis. Each case must be studied by itself, with the mechanics of this portion of the spine borne carefully in mind. Concerning treatment, in the very early cases a great deal can be accomplished by teaching the children to stand in a proper position, that is, when the processes are small and show an inclination to unlock. That inclination is best shown when 
the roentgenogram of a child is taken in the standing position, with the lumbar spine in the position of lordosis and weight-bearing. It can be treated by exercises for the purposes of muscular development, producing a flat back and no lordosis. In the more severe cases, with a large transverse process on one side, surgical measures are demanded.

\section{PLAGUE IN HAVANA}

\author{
G. M. GUITERAS, M.D. \\ Surgeon, United States Public Health Service \\ WASHINGTON, D. C.
}

The first case of plague known to occur in Havana, Cuba, was discovered July 6, 1912, in the person of a Spaniard residing at No. 2 Mercaderes Street. Two additional cases occurred July 12 and 22 at Justiz and Baratillo streets, about four blocks distant from the first case. The district involved in this infection is about three blocks from the water front and in the wholesale commercial district of the city.

The infection was at first supposed to have been imported from Porto Rico, the capital of which, San Juan, was at the time plague infected. Subsequent investigation, however, by the Cuban health authorities, indicates that the infection was a direct importation from the Canary Islands, where plague was present at the time, though concealed and stubbornly denied by the Spanish authorities.

Owing to the early discovery of the disease and the thorough and excellent work of the Cuban Sanitary Department this outbreak was confined to the three cases mentioned above.

About one year and a half later, that is, Feb. 22, 1914 , the first case of plague of the present outbreak was discovered in Havana at No. 1 Officios Street, which is in the block adjacent to that in which the first two cases occurred in 1912. Whether this second appearance of plague was simply a continuation of the old infection or a new importation is a moot question. The former is the more reasonable view and is supported by Dr. Juan Guiteras, Director of Health of Cuba. The case of February 22 was followed by twenty-four other cases, making a total of twenty-five within the city of Havana. The last case occurred June 22.

Two other cases were found in the neighborhood of Havana, the first at Artemisa, 45 kilometers to the southwest of the city, April 18, the second at San Jose de las Lajas, a town about 25 kilometers southeast from Havana, June 15. As the infection in both these cases was clearly traceable to Havana and they were treated in that city, these properly belong with the Havana series.

May 30 an infected rat was found in the freight station in the town of Jaruco, 37 kilometers to the eastward of Havana on the railway between that city and Matanzas. The station and surrounding structures were disinfected and there were no further developments.

June 23 a case suspicious of plague was reported from Santiago de Cuba in the eastern extremity of the island. Later it was confirmed, after inoculation tests and the exposure of guinea-pigs in the infected locality had shown positive results. Plague-infected rats were found about the same time.

It may be considered as more than probable that the spread of plague infection outside of the original focus in Havana was due to the action of a Mr. Gonzales, a wholesale provision merchant who, when one of his employees sickened with what he thought might be plague, and later was confirmed as such, concealed it, and, knowing that as soon as the case was discovered his warehouse would be quarantined and funigated, disposed of as much of his stock as possible, sending it to various parts of the city of Havana and throughout Cuba, including the subsequently infected points, San Jose de las Lajas, Jaruco and Santiago de Cuba. $\mathrm{He}$ is at present being prosecuted before the courts.

It should be observed that two weeks prior to the appearance of the first case of the present outbreah in Havana, the sanitary authorities had noted some rat mortality. Anti-rat measures were put into effect at once, even before the discovery of the first human case of plague. With a few exceptions all the cases may be traced directly or indirectly to the original focus near the Havana water front.

A secondary well-marked focus developed later in the extensive stables of the Department of Public Works in Figuras Street. Two infected rats were found here, the first, April 17, the second, April 24. These are the only infected rats found in Havana. This focus gave rise to six cases.

On account of the character of the stable buildings and grounds, disinfection by the usual methods was futile and the Sanitary Department decided to destroy the infection by fire. The stables and everything within them, except the animals, carts and harness, were converted into ashes, April 25. This radical measure was effective in destroying a very menacing focus of infection. No other case developed from this source, except perhaps Case 25, in which the place of business of the patient, No. 2 Concha Street, was on the route taken by the employees, animals and equipment of the stables destroyed, when they were moving into new quarters.

\section{SANITARY ORGANIZATION}

Sanitary measures throughout the Island of Cuba are under the control of the Department of Health and Charities, the head of which is a cabinet officer. The secretary of this department, which is, in truth, a department of public health, is at present Dr. Enrique Nunez, a physician of ability. The actual work of sanitation, however, is in charge of the Director of Health, Dr. Juan Guiteras, and a very capable corps of assistants.

Every municipality throughout the island has a chief sanitary officer reporting to the Director of Health. In Havana the government maintains the well-known "Las Animas Hospital" for the care and treatment of all cases or suspected cases of communicable diseases, which hospital is in charge of the Director of Health, as is also the well-equipped laboratory connected with the department. In normal times a personnel of about 100 men is kept on duty inspecting, fumigating and rat-catching. In times of epidemic outbreaks, as in the present case, this number is very materially increased. An official bulletin is published monthly by the department, containing interesting morbidity and mortality statistics and original articles of value, the more important being published in Spanish, English and French. The general organization of the department makes for quick and efficient work.

The sanitary measures put in force during the present outbreak of plague are directed primarily against 